\title{
Optimal Planning of Fault Current Limiters for Recloser-Fuse Coordination in Distribution Systems with DGs

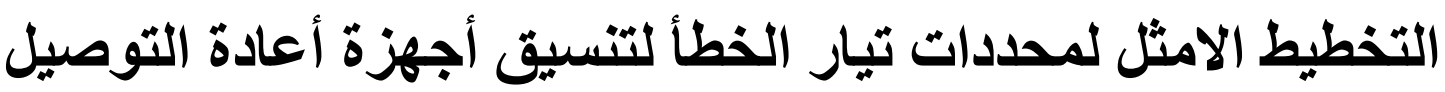 \\ التثقائى والقيوزات فى نظم التوزيع مع وجود المولدات الموزعه
}

Akram. Elmitwally, Eid. Gouda, Saad Eskander, Elsayed. Adawy

Electrical Engineering Department, Mansoura University, Mansoura 35516, Egypt

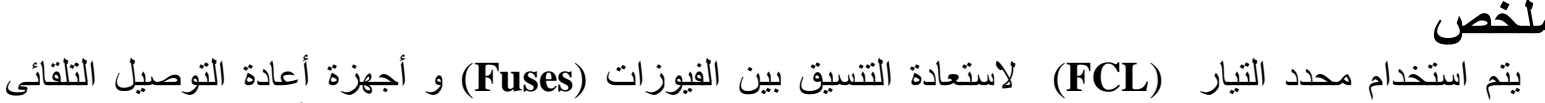
(Recloser)

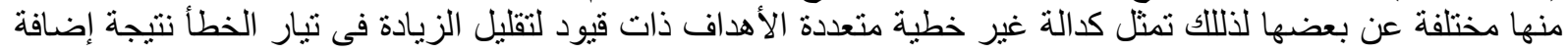

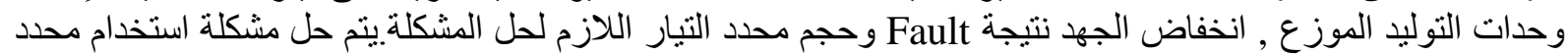
التيار باستخدام Multi objective Particle Swarm Optimization. عندما تم التطبيق على أكثر من نظام وجد أنه عندما تكون المشكلة متعددة الأهداف أفضل فى النتائج عن المشكلة ذات الهدف والخد الحد حيث تم تقليل التيار ألى حد كبير

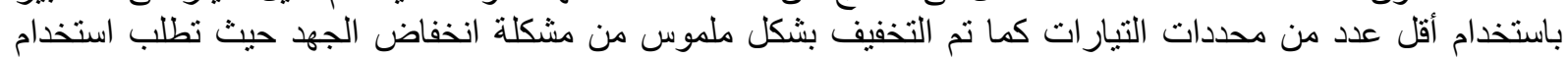

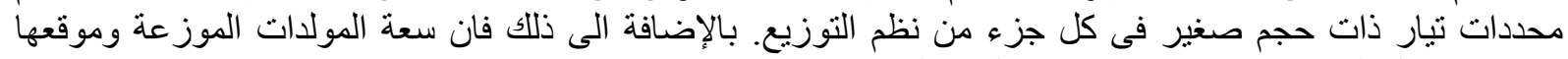

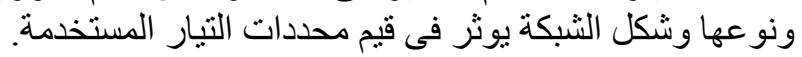

\begin{abstract}
In this paper, the fault current limiter (FCL) is used to restore the coordination between the protection devices in distribution systems with high-level of DG penetration. The FCL allocation may be described as an optimization problem involving multiple objective functions which are contradictory and of different dimensions. So, it is formulated as a multi-objective constrained nonlinear programming problem. The interaction among different objectives gives rise to a set of compromised solutions, largely known as the Paretooptimal solutions. The objectives are to simultaneously minimize: the increase in fault current levels due to the penetration of DG, voltage sag, and the total cost (size) of required limiters. The optimization problem is solved using Particle Swarm Optimization (PSO). The method is applied to two distribution test systems. Effects of different operating factors are assessed and comparative analysis of results is provided.
\end{abstract}

\section{Keywords}

Fault current limiter, Voltage sag, DG

\section{Introduction}

Distributed generation (DG) is small generation units, integrated to low or medium voltage distribution systems. DG can provide emergency energy source, mitigate voltage violations, improve service continuity, reduce power losses, and lessen undesired gas emissions [1]-[4]. Distribution protection system incorporates relays, reclosers and fuses. Reclosers are usually installed on main feeders with fuses on laterals. Reclosers lower service interruptions because about $80 \%$ of faults that occur in distribution systems are temporary. A recloser can clear a temporary fault before allowing a fuse to blow. Operation coordination of fuses, reclosers and relays is a crucial issue [5].

DG integration to a distribution network causes changes in fault current. So, the coordination between the protection devices is not assured. Many factors, such as size of 
DG, location of DG, and type of DG (static or rotating machine), would influence the share of DG in total fault current [2]. The impact of DG on overcurrent protection devices in radial distribution systems is investigated in [6]-[15]. Many problems occur because of DG integration. They include fuse fatigue, nuisance fuse blowing, and recloser-fuse mis-operation.

Several methods have been proposed to keep coordination of protection devices in presence of DG [6]-[9]. Ref. [6] determines the maximum capacity of DG that would assure coordination between the recloser and fuses on a feeder. But this method limits the size of DG connected to a system blocking other operational benefits of DG. In [7], Brahma and Girgis discussed a microprocessor-based reclosing scheme to keep recloser-fuse coordination on a feeder with a high penetration level of DG. A method to modify recloser characteristics to achieve coordination is also described. The method assumes that DG will be disconnected before the recloser operates at the first time, which means that the DG status must be continuously monitored. Also, disconnecting the DG at every fault occurrence may degrade service reliability and quality because the faults on distribution feeders may be frequent and temporary. In [8] discussed Coordination of Voltage Sag and Overcurrent Protection in DG System. In [9] Brahma and Girgis discussed the development of adaptive protection scheme for distribution systems With high penetration of distribution generation. Ref[16] discuss technique for recloser-fuse coordination in distribution systems with distributed generation.

Fault Current Limiter (FCL) has emerged as an active and effective way to limit fault currents [17], [18]. It provides a sudden extra impedance in the way of the fault current. Examples of FCL devices are explosive limiters, solid state FCL, and superconducting FCL [17]. In general, a FCL provides a small impedance under normal system operating conditions and a large impedance during fault conditions. FCLs may lower system reliability, increase cost, and increase operational complexity [19]. Application of FCLs for keeping protection coordination is analyzed in [18]-[20]. The merits of FCLs greatly depend on their sizes and locations [21]. In [15], a genetic algorithm is used to find the optimal FCLs to minimize fault current under DG integration. The same is done in [22] using Particle Swarm Optimization (PSO). The method is applied to a small-scale simple test system. Usually, locations of FCL are assumed. Then, a simplified single-objective optimization problem is solved to get the size of FCL. The cost of FCLs is generally high as it typically involves power electronics or superconducting devices [17]. The FCL cost depends on the resistive and inductive elements sizes (values). The total size of determined FCLs might be prohibitively large that limit the economic feasibility of applying FCL. So, special care should be given to FCLs size when FCL installing is studied to reduce stress on power network equipment or to maintain protection coordination. Hence, if the planner main objective is to achieve protection devices coordination by FCLs, another crucial objective must be minimizing the size of the required FCLs. Besides, voltage sag accompanies the occurrence of faults. It can cause tripping of critical loads leading to serious consequences. Voltage sag is mitigated by proper setting and coordination of overcurrent protection devices [8]. So, if overcurrent protection devices coordination is concerned on one side, the voltage sag level must be considered on the other side. Allocation of FCLs can be done in such a way that it optimizes average voltage sag in the network. Nonetheless, optimizing FCL cost and voltage sag level are not tackled in the reported FCL planning studies.

In this paper, FCL is used to restore the recloser-fuse coordination without disconnecting DG. The FCL allocation problem involves multiple objectives which are contradictory and of different dimensions. 
The novel aspects in the paper are:

* The FCL allocation problem is formulated as a multi-objective constrained nonlinear programming problem. The objectives are to simultaneously minimize: the increase in fault current levels due to the penetrating of DG, average voltage sag level, and the total cost (size) of the required FCLs.

* Both the FCLs locations and sizes are searched. The FCLs locations are not assumed in advance like other studies. This results in much reduced total size of FCLs.

* Effects of DG size, location, type, network configuration and FCL type are investigated.

The proposed method is applied to both small-scale and large-scale test distribution networks. Comparative analysis of results is presented. The interaction among different objectives gives rise to a set of compromised solutions, known as Pareto-optimal solutions [22]. The optimization problem is solved using Particle Swarm Optimization (PSO).

\section{Protection Coordination}

Fig. 1 depicts the protection scheme in a typical distribution network. Fuse must isolate permanent faults of the lateral feeder. Recloser has two modes, fast mode that trips the circuit for temporary fault before the fuse operates, and slow mode that serves as backup protection when a fuse fails to blow up. The breaker is used as the entire backup protection when both the recloser and lateral fuses fail to isolate a fault on the feeder. A fuse has two characteristics: "Minimum Melting (MM) and Total Clearing (TC)". Breakers and reclosers are normally equipped with reverse-time overcurrent relays having the characteristics given in (1) [13].

$$
\mathrm{t}(\mathrm{I})=T D\left(\frac{A}{M^{P}-1}+B\right)
$$

where $A, B$ and $p$ are constants for particular curve characteristics; $t$ is operating time of device; $M$ is ratio of $\frac{I}{\text { Ipickup }}\left(I_{\text {pickup }}\right.$ is the relay current set point) and $T D$ is time dial setting. The characteristic of fuses is similar to reverse-time overcurrent relay characteristic. General equation of fuses follows (2) [13].

$\log (t)=a \log (I)+b$

where $t$ and $I$ are the associated operating time and current, and the coefficients $a$ and $b$ are calculated from curve fitting.

\section{Substation}

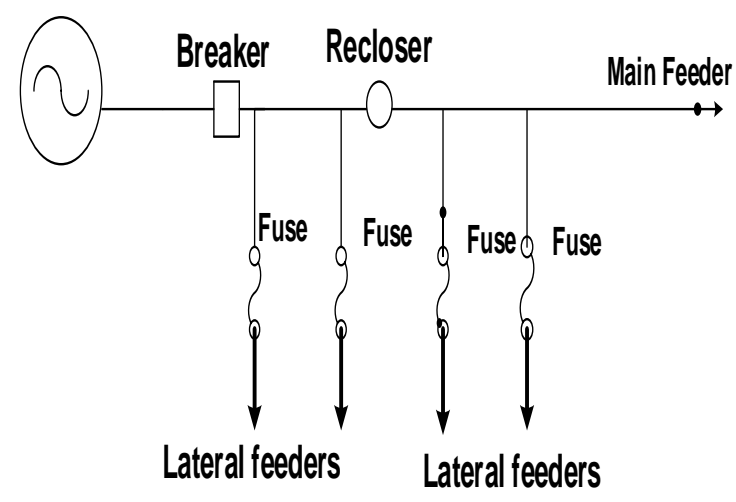

Fig.1 Typical radial distribution feeder

\section{A. Breaker-breaker mis-coordination}

Fig. 2 shows a distribution system with two radial feeders. When a fault occurs at the upper feeder, the circuit breaker at this feeder must operate. But the circuit breaker at the lower feeder may operate because the DG feeds a fault current and it may lead to unnecessary electricity interruption on this healthy feeder. The solution for the false tripping on healthy feeders is using a directional overcurrent relay for the circuit breaker. Another solution for this problem is using same or similar circuit breakers for both feeders [13]. 


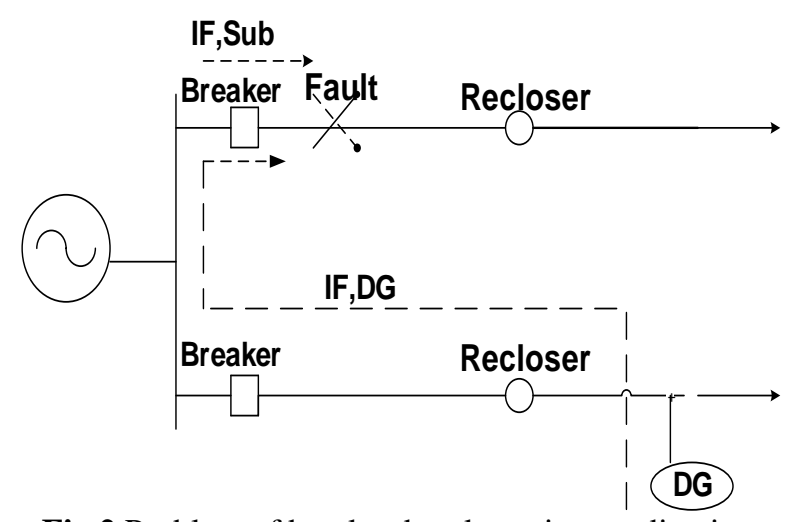

Fig.2 Problem of breaker-breaker mis-coordination

\section{B. recloser-fuse mis-coordination}

Fig.3 presents the time-current characteristics of the recloser and the fuse, as well as the short-circuit current across the fuse before and after connecting DG. The penetration of DG will cause miscoordination between fuse and recloser. When a fault occurs at the lateral feeder (see Fig.1), the recloser at fast mode operates (opens) first to isolate the presumed temporary fault. If the fault still remains when the recloser closes again after a specific time, the fuse at the lateral feeder should blow up to isolate the fault that is actually a permanent fault. If the fuse fails to operate, the recloser at slow-mode will operate as a backup protection. To obtain this sequential operation, the fault current must rest between the minimum and maximum currents shown in Fig.3.

To illustrate the problem, a connected DG is assumed at the downstream end of a main feeder. If a fault occurs at a lateral feeder downstream the recloser, the fault current seen by the recloser will be lower than that seen by the fuse because of the fault current fed from DG. Fig. 3 shows the fault currents flowing through the recloser and the fuse for this case. With these different fault currents seen by the fuse and recloser, fuse blowing may occur before the recloser acts that means loss of recloser-fuse coordination. To restore coordination, utilities can replace the protective devices with higher rating devices to fit the extra fault current from DG. This may not be a good solution because the cost of replacement and setting are considerable compared to the economic benefits from DG.
Alternatively, DG fault current that impacts the existing protection coordination must be limited to a specific margin [13]. From Fig.3 , one can write:

$I_{\text {fuse, } \text { margin }}=I_{S}+I_{\text {margin }}$

Where,

IS is fault current from utility substation;

$I_{\text {margin }}$ is margin for DG fault current;

$I_{\text {fuse,margin }}$ is current seen by fuse with $I_{\text {margin }}$ from DG.

To ensure that the recloser in fast mode will operate before fuse in MM mode, the fault current from DG must be lower than $I_{\text {margin, }}$, that is:

$\mathrm{I}_{\mathrm{DG}}<\mathrm{I}_{\text {margin }}$

where $\mathrm{I}_{\mathrm{DG}}$ is the fault current from DG.

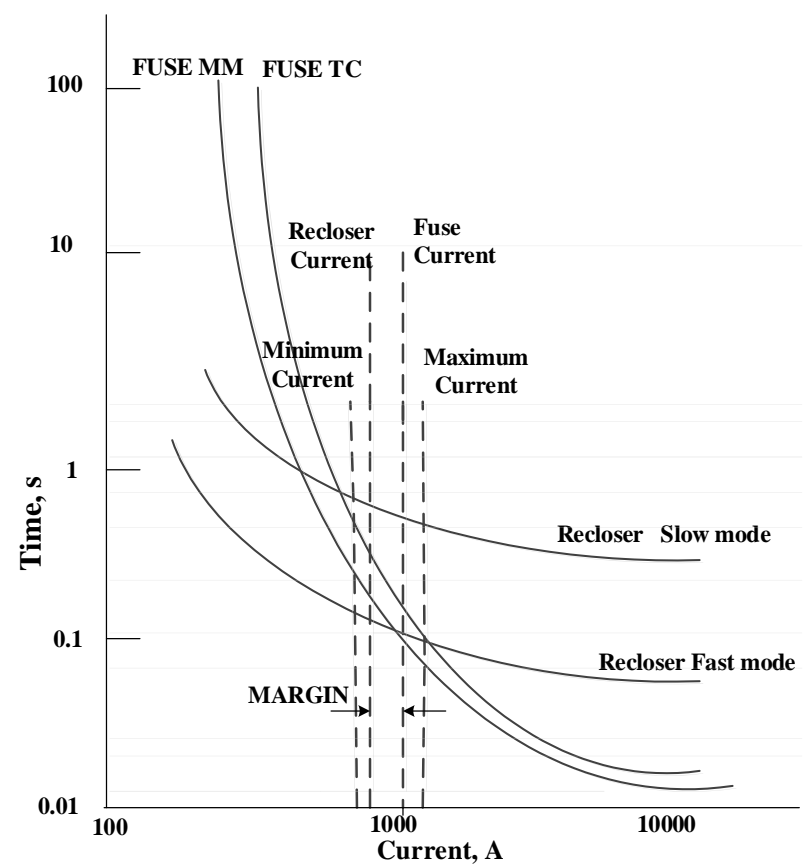

Fig. 3 Sample coordination of breaker, recloser, and fuse

\section{Problem Formulation}

Two configurations are defined for a distribution network:

Configuration A: Grid with all DG disconnected.

Configuration B: Grid with all DG connected.

Configuration $A$ represents the base case for which the settings of protective devices are 
designed. The short circuit currents of this configuration will be used as the reference values for configuration $B$. The optimization problem is formulated such that the changes in fault currents passing through main and backup protective devices are minimized by optimal allocation of FCLs. Meanwhile, the cost of the required FCLs is to be minimized. Assuming the same cost for the per unit inductive impedance and the per unit resistance, the p.u cost of FCLs is the same as the p.u size. The increased fault current level after DG integration causes higher voltage drop on feeder sections and increased voltage sag at most of nodes. This is a severe power quality problem that results in loss of productivity due to undesired load tripping. Hence, it is targeted herein to minimize the average voltage sag of the system nodes.

The three objective functions are expressed as:

$$
\begin{aligned}
& \text { Min } F_{1}=\sum_{i=1}^{N} a b s\left(I_{\text {fuseBi }}-I_{f u s e A i}\right)+ \\
& \sum_{m} a b s\left(I_{r p B m}-I_{r p A m}\right)+\sum_{n=1}^{N} a b s\left(I_{r b B n}-\right. \\
& \left.I_{r b A n}\right) \\
& \text { Min } F_{2}=\sum_{k=1}^{L}\left(R_{k}+X_{k}\right) \\
& \text { Min } F_{3}=1-\frac{\sum_{i=1}^{M} \sum_{j=1}^{M} v_{i}^{j}}{M^{2}}
\end{aligned}
$$

Where, $I_{f u s e B i}$ and $I_{f u s e A i}$ represents the fault current of fuse $i$ due to a fault downstream the fuse with DG and without DG, respectively. $\mathrm{N}$ is the number of fuses in the system. The variables $I_{r p B m}$ and $I_{r p A m}$ represent the recloser primary operation current due to nearby faults downstream the $\mathrm{m}^{\text {th }}$ recloser with and without the DG, respectively. The variables $I_{r b B n}$ and $I_{r b A n}$ represent the recloser backup operation current for faults downstream of the $\mathrm{n}^{\text {th }}$ fuse with and without the DG, respectively. $R_{k}$ and $X_{k}$ represent the resistance and inductive reactance of the $k^{\text {th }}$ FCL. $V_{i}^{j}$ is the p.u voltage at bus $i$ for a three-phase fault at bus $j$ and $M$ is the number of buses. $\operatorname{Equ}(7)$ is used to increase the average voltage at each bus for each fault and try to reach it to standard 1p.u. The above problem is solved subject to:
$\mathrm{R}_{\text {min }} \leq \mathrm{R}_{\mathrm{k}} \leq \mathrm{R}_{\max }$

$\mathrm{X}_{\min } \leq \mathrm{X}_{\mathrm{k}} \leq \mathrm{X}_{\max }$

$\mathrm{I}_{\mathrm{h}, \mathrm{B}}-\mathrm{I}_{\mathrm{h}, \mathrm{A}}<\varepsilon$

Where,

$\mathrm{R}_{\min }$, and $\mathrm{R}_{\max }$ are lower and upper limits of $\mathrm{R}_{\mathrm{i}}$.

$\mathrm{X}_{\min }$, and $\mathrm{X}_{\max }$ are lower and upper limits of $\mathrm{X}_{\mathrm{i}}$.

$I_{h, B}$ is current of $h^{\text {th }}$ feeder section after DG connection.

$I_{h, A}$ is current of $h^{\text {th }}$ feeder section before DG connection.

$\varepsilon$ is tolerance error.

\section{Iv. Particle swarm optimization}

Single-objective PSO (SOPSO) and multiobjective PSO (MOPSO) are used to solve many power system optimization problems [23], [24].The decision of each individual in PSO depends on own experience together with other individuals' experiences. The individual particles are drawn randomly toward the position at present velocity of each individual, their own previous best performance, and the best previous performance of their neighbors [23], [24].

The solution set of a problem with multiple objectives does not consist of a single solution. But, it is aimed to find a set of different solutions (the so-called Pareto optimal set). Solving a multi-objective problem requires maximizing the number of elements of the Pareto optimal set and maximizing the spread of solutions to make distribution of vectors as smooth as possible [22]. On extending PSO to MOPSO, one must decide how to select particles to give preference to non-dominated solutions, and how to maintain diversity in the swarm to avoid convergence to a single solution [23].

\section{Solution Algorithm}

Each FCL is allowed to have a resistive and inductive component. Thus, with a maximum of FCLs to be connected to the system in Fig.5. The MOPSO-based solution algorithm is implemented as given below. 
1. Considering a three-phase solid fault at a given bus, disconnecting all DG in the system, the short circuit currents seen by each protective device are calculated.

2. Generate an initial population of particles with initial velocities for the 22 variables to be optimized.

3. The new short circuit currents seen by each protective device for each particle with DG connected and FCL in place are calculated.

4. For each particle, calculate its fitness value using the objective functions values given in (5)-(7). To evaluate the performance of individual particles, a dynamic weighted aggregating approach is used to construct the fitness function for MOPSO [25]. It is expressed as follows:

$$
\begin{gathered}
\text { fitness }=1 / \sum_{i=1}^{Q} w_{i} F_{i} \\
\text { where, }
\end{gathered}
$$

$\mathrm{w}_{\mathrm{i}}$ is a weighting factor such that $\sum w_{i}=1$. $F_{i}$ is the value of the $i^{\text {th }}$ objective function. $\mathrm{Q}$ is the number of objective functions.

5. Each particle's current fitness value is compared with the particle best position found (pbest), if the fitness value is greater than ( $p$ best), change the particle best position with the new fitness function value.

6. Determine the current global best position (gbest) among all particles' pbest. Compare the current gbest position with the previous gbest position and update gbest.

7. For all particles, update the position and velocity of all dimensions as in [23].

8. Repeat steps 1-7 until the preset number of iterations is completed.

The flowchart for planning the FCL using PSO is shown in Fig. 4.

\section{Application}

The proposed MOPSO-based FCL planning algorithm is developed in MATLAB environment. It is applied to two test systems.

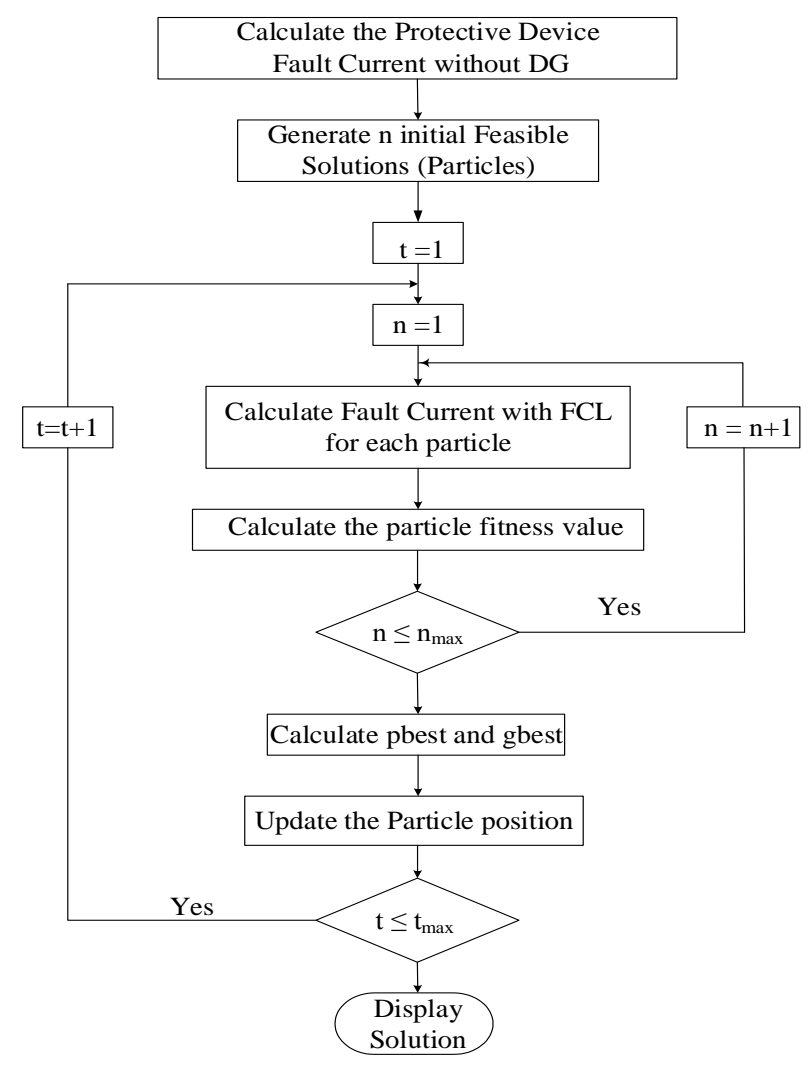

Fig. 4 Flow Chart of planning the FCLs using PSO

\section{A. Canadian benchmark system}

Fig.5 presents a part of the Canadian benchmark system as a typical distribution system [22]. Each feeder is protected by a recloser. Fuses are used to protect the lateral feeders as shown in Fig.5. The system includes two 8 MVA synchronous machinebased DG. The DGs will feed additional fault current and it may cause loss of coordination of protective scheme. Thus, it is targeted to maintain recloser-fuse coordination by optimal placement and sizing of FCLs. The system data as well as the PSO data is given in Table I. A maximum of 11 active FCLs are allowed to be inserted in series to: each DG unit, utility source, and each feeder section. Each FCL is composed of a resistive component and an inductive component connected in series.

\section{Base case: complete problem with voltage sag}

Solving the multi-objective optimization problem formed in section $\mathrm{V}$ above, the results are given in Table II. The values of the three objective functions are $\mathrm{F} 1=1.2357$ p.u, $\mathrm{F} 2=2.0636+\mathrm{J} 1.4113$ p.u, $\mathrm{F} 3=0.6814$ p.u. 
Eleven FCLs are found necessary as shown in Fig.6. The biggest FCL sizes are next to the three power sources. Smaller FCL sizes are needed in feeder sections. Table II presents the symmetrical fault currents passing through the various protective devices under three evaluation conditions, without DG, with DG but without FCL, and with both DG and FCLs. The fuse currents are denoted as IF and the relay currents are denoted as IR. The symbols $\mathrm{P}$ and $\mathrm{B}$ represent the primary and backup operation. It is noted that application of optimal FCLs can reduce fault current to be nearly the same as its values before DG is integrated. This assures that no protection mis-coordination occurs. Fig.7 depicts the node voltages for different symmetrical fault locations when the optimal FCLs are installed. It also compares the results for the case without DG and without FCL under DG. The FCL presence much improves the node voltage under fault conditions. This improves voltage sag and lessens the probability of critical loads tripping under fault conditions.

Table I: simulation data

\begin{tabular}{|c|c|}
\hline Feeder Data & $\begin{array}{c}700 \text { MCM Cu XLPE cable with } \\
\text { impedance }=0.1529+\mathrm{j} 0.1406 \Omega / \mathrm{km} \text {. }\end{array}$ \\
\hline Utility Data & MVAsc $=500 \mathrm{MVA}$ and $\mathrm{X} / \mathrm{R}=6$ \\
\hline Utility Transformer T1 & 20 MVA, $115 \mathrm{kV}$ to $12.47 \mathrm{kV}, X=10 \%$ \\
\hline Base kV & $12.47 \mathrm{kV}$ \\
\hline DG Reactance (x\%) & $9.67 \%$, \\
\hline DG Transformer & $5 \%, 12.47 \mathrm{kV} / 480 \mathrm{~V}$ \\
\hline $\begin{array}{l}\text { Maximum number of } \\
\text { iterations }\end{array}$ & 2000 \\
\hline $\begin{array}{l}\text { Maximum number of } \\
\text { particles }\end{array}$ & 1000 \\
\hline
\end{tabular}

Table II: protection device fault currents using mopso, p.u

\begin{tabular}{|c|c|c|c|}
\hline & No DG & With DG and no FCL & $\begin{array}{c}\text { With DG and } \\
\text { FCL }\end{array}$ \\
\hline IF1 & 1.3526 & 2.3564 & 1.7402 \\
\hline IF2 & 1.2557 & 2.0871 & 1.1876 \\
\hline IF3 & 1.1808 & 1.8937 & 0.9428 \\
\hline IF4 & 1.1030 & 1.7030 & 0.7775 \\
\hline IF5 & 1.3210 & 2.3228 & 1.7340 \\
\hline IF6 & 1.2456 & 2.0830 & 1.3176 \\
\hline IF7 & 1.2123 & 1.9973 & 1.0265 \\
\hline IF8 & 1.1291 & 1.7823 & 0.7835 \\
\hline IR1(P) & 1.4343 & 1.9627 & 1.3212 \\
\hline IR2(P) & 1.4343 & 1.9653 & 1.2881 \\
\hline IR1(BF1) & 1.3526 & 1.8167 & 1.6853 \\
\hline IR1(BF2) & 1.2595 & 1.6139 & 1.1535 \\
\hline IR1(BF3) & 1.1879 & 1.4673 & 0.9177 \\
\hline IR1(BF4) & 1.1119 & 1.3209 & 0.7575 \\
\hline IR2(BF5) & 1.3330 & 1.7841 & 1.6680 \\
\hline IR2(BF6) & 1.2607 & 1.6047 & 1.2808 \\
\hline IR2(BF7) & 1.2378 & 1.5418 & 0.9923 \\
\hline IR2(BF8) & 1.1655 & 1.3772 & 0.7582 \\
\hline
\end{tabular}

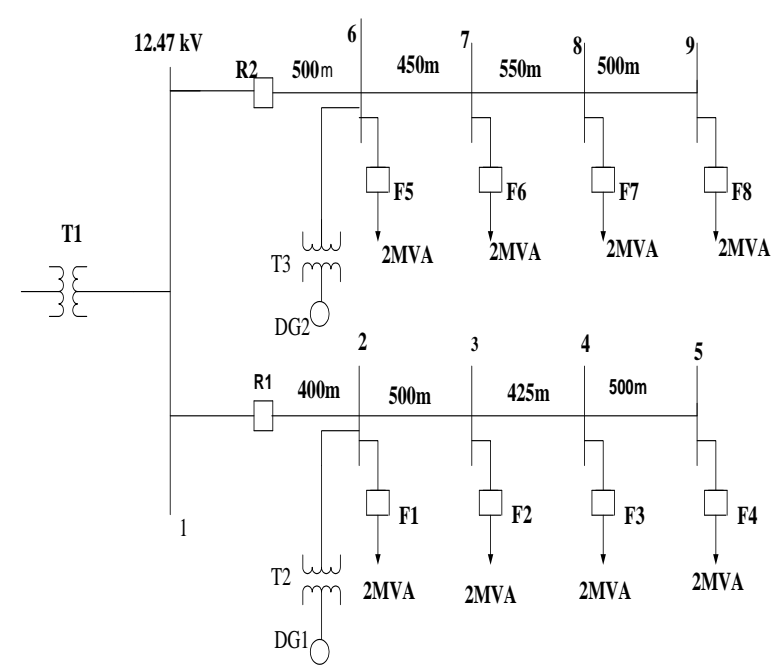

Fig.5 Canadian benchmark test system

\section{Comparative evaluation}

Using a single objective function (only F1 given in (5)), three FCLs are found sufficient. Their locations are at the utility source and at each DG unit. Their optimal component values are provided in bottom cell of fourth column in Table III. The same results are almost obtained in [22]. On the other hand, when the proposed multi-objective formulation is applied considering only the two objectives F1, F2 (without voltage sag), only one inductive FCL with impedance $0+\mathrm{j} 0.7401 \mathrm{p} . \mathrm{u}$ is found sufficient at the utility source. Table III presents the fault currents passing through the various protective devices without DG, with DG but with no FCL, and with both DG and the FCLs for SOPSO (F1) and MOPSO (F1 and F2) cases. Strategic locations, usually next to power sources, can be selected for placing FCLs and the problem is solved to get the FCLs sizes. Table IV shows the fault currents passing through the various protective devices for different FCLs locations under DG. The FCLs components sizes are determined using MOPSO with two objectives $\mathrm{F} 1$ and $\mathrm{F} 2$ and provided in the bottom of Table IV.

For both the single objective and multiobjective formulations, the FCLs keep the fault current levels close to the original values (without DG). The small increase in branch fault current is always less than the margin allowed to maintain coordination as discussed in section II. Assuming the device 
inverse characteristics as given in Fig.3, the inclusion of FCLs in optimal locations and protection coordination is assured even with sizes.

the two DG units connected due to the

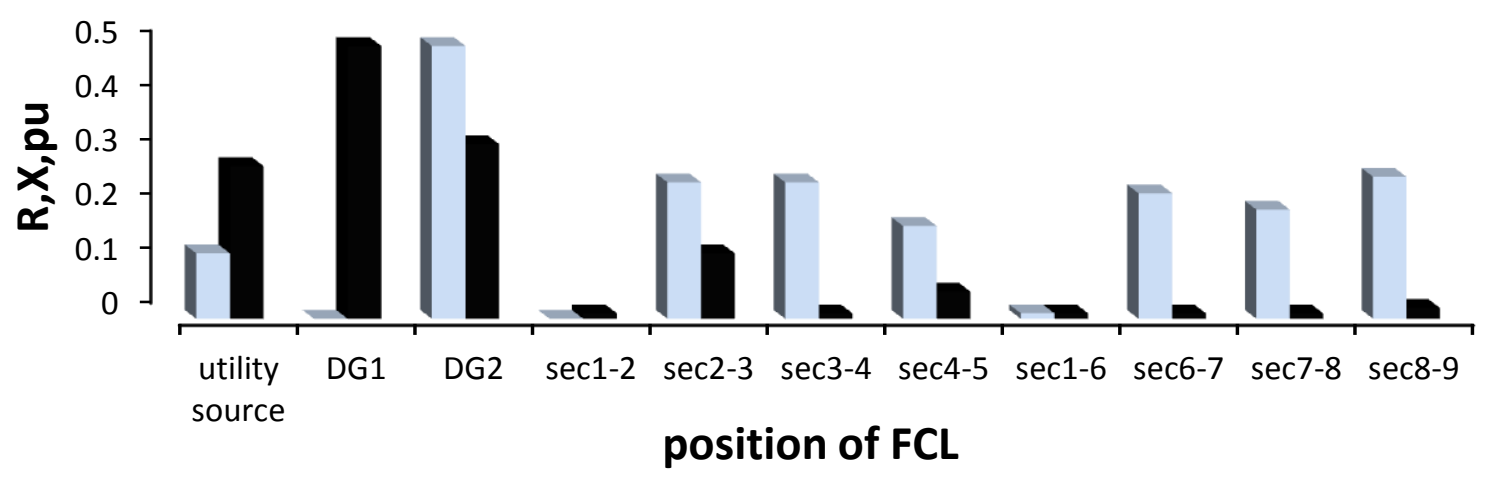

Figure.6 Components R, X of the determined FCLs

Table III : protection devices fault currents in p.u and pso results

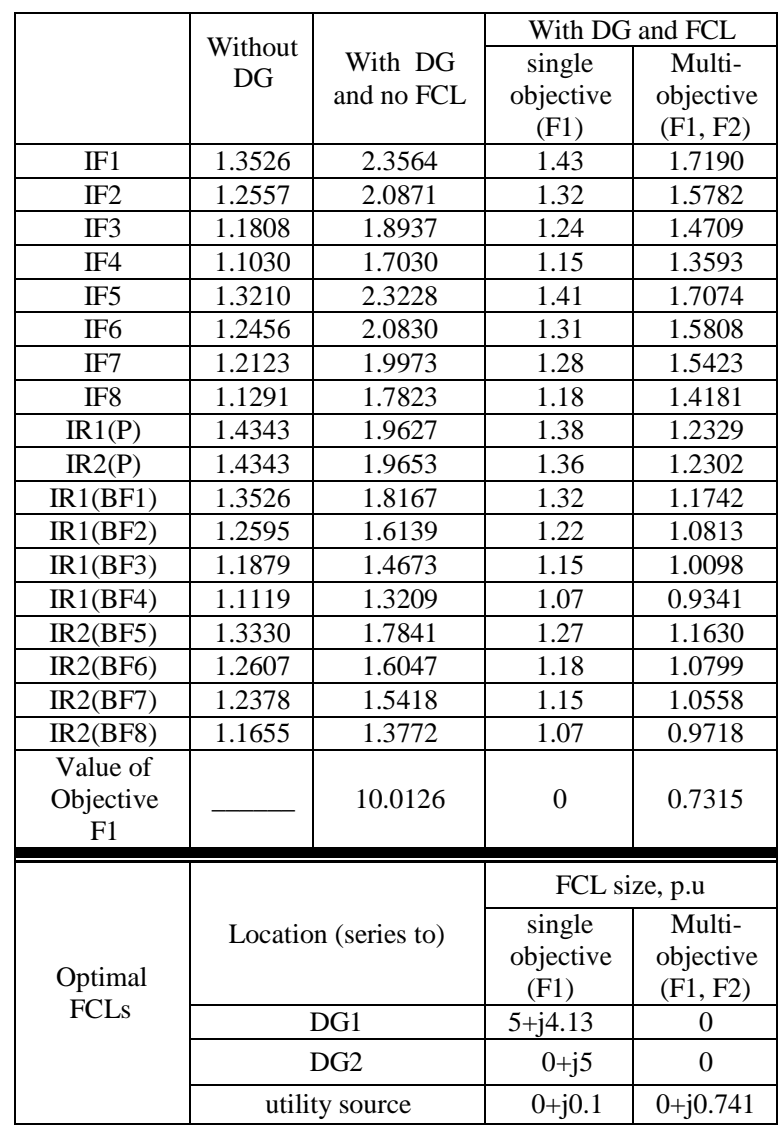



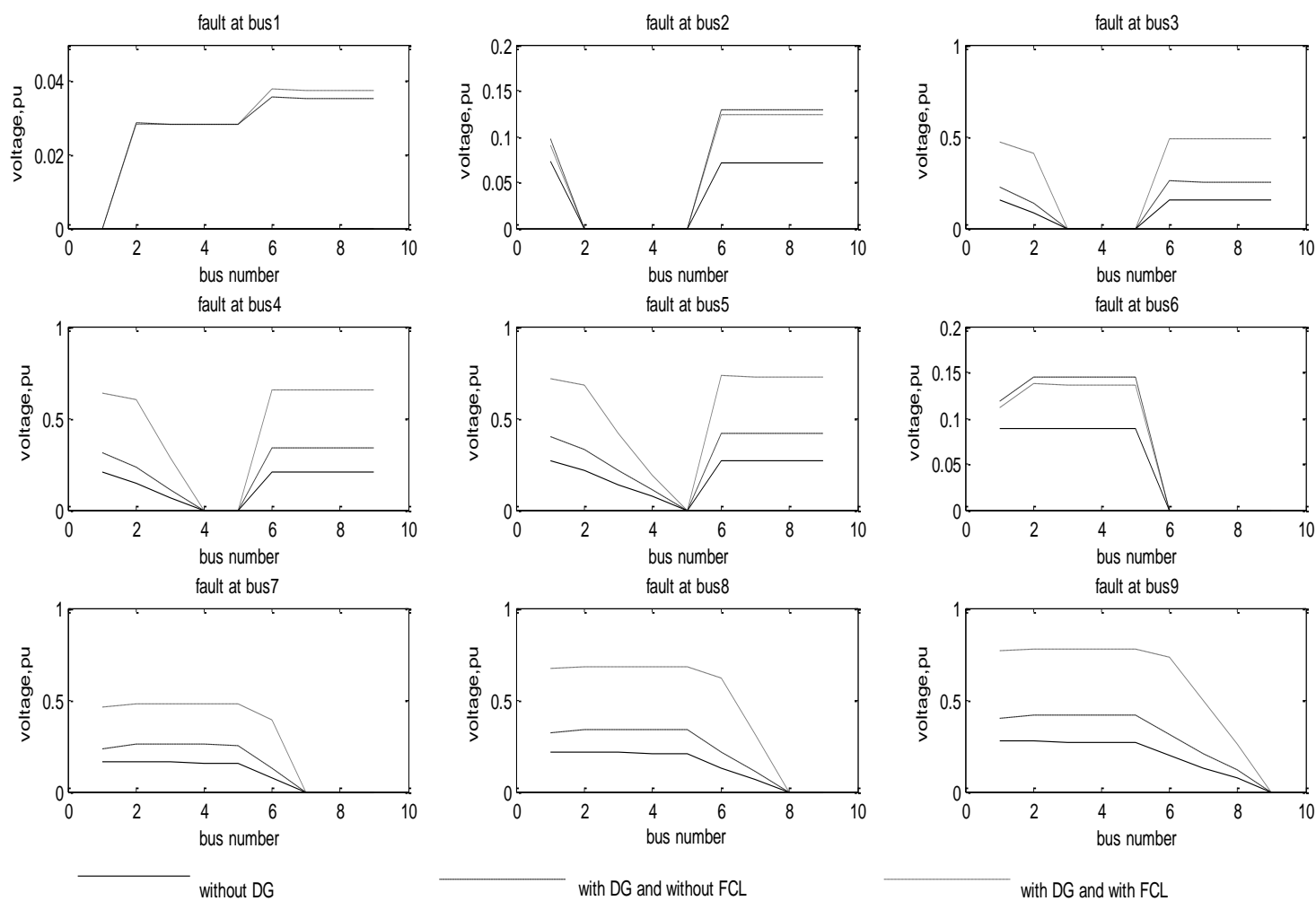

Fig.7 Node voltage for different symmetrical faults

Table IV protection devices fault currents for various fcl placement strategies using mopso, p.u

\begin{tabular}{|c|c|c|c|}
\hline & $\begin{array}{c}\text { With } \\
\text { source } \\
\text { FCL Only }\end{array}$ & $\begin{array}{l}\text { With DG } \\
\text { FCL only }\end{array}$ & $\begin{array}{c}\text { With DG } \\
\text { and source FCL }\end{array}$ \\
\hline IF1 & 1.7190 & 1.5940 & 1.5278 \\
\hline IF2 & 1.5782 & 1.4476 & 1.4108 \\
\hline IF3 & 1.4709 & 1.3416 & 1.3217 \\
\hline IF4 & 1.3593 & 1.2355 & 1.2289 \\
\hline IF5 & 1.7074 & 1.57 & 1.5111 \\
\hline IF6 & 1.5808 & 1.44 & 1.4064 \\
\hline IF7 & 1.5423 & 1.3786 & 1.3712 \\
\hline IF8 & 1.4181 & 1.2655 & 1.2700 \\
\hline IR1(P) & 1.2329 & 1.4756 & 1.3435 \\
\hline IR2(P) & 1.2302 & 1.4841 & 1.3468 \\
\hline IR1(BF1) & 1.1742 & 1.4466 & 1.2746 \\
\hline IR1(BF2) & 1.0813 & 1.3177 & 1.1805 \\
\hline IR1(BF3) & 1.0098 & 1.2237 & 1.1082 \\
\hline IR1(BF4) & 0.9341 & 1.1280 & 1.0314 \\
\hline IR2(BF5) & 1.1630 & 1.4289 & 1.2607 \\
\hline IR2(BF6) & 1.0799 & 1.3146 & 1.1768 \\
\hline IR2(BF7) & 1.0558 & 1.2611 & 1.1497 \\
\hline IR2(BF8) & 0.9718 & 1.1587 & 1.0659 \\
\hline & \multicolumn{3}{|c|}{ FCL size, p.u } \\
\hline $\begin{array}{l}\text { Location } \\
\text { (series to) }\end{array}$ & $\begin{array}{c}\text { With } \\
\text { source } \\
\text { FCL Only }\end{array}$ & $\begin{array}{l}\text { With DG } \\
\text { FCL only }\end{array}$ & $\begin{array}{c}\text { With DG } \\
\text { and source FCL }\end{array}$ \\
\hline DG1 & & 4.2805 & $0.045+\mathrm{j} 2.0839$ \\
\hline DG2 & & $4.48+j 0.0019$ & $0.0312+\mathrm{j} 2.1263$ \\
\hline $\begin{array}{l}\text { utility } \\
\text { source }\end{array}$ & j0.7401 & & $0.0086+j 0.2163$ \\
\hline $\begin{array}{c}\text { Value of } \\
\text { Objective } \\
\text { F1 } \\
\end{array}$ & 0.7315 & 1.93 & 0.4087 \\
\hline
\end{tabular}


It is worthy noting that the proposed multiobjective formulation results in less number and sizes of FCLs required to maintain protection coordination under DG in comparison to the single-objective formulation. This provides technical simplicity and economic savings to the distribution network operators. To reduce the solution time, by reducing the search space, one can assume the FCLs locations and searches only the FCLs components sizes. Three candidate sets of FCL locations are evaluated as given in Table IV. The first is to locate a FCL after the utility source. The second is to locate a FCL in series to each DG unit. The third is to locate a FCL in series to each power source (the utility and DG). The FCL after Source is found the best place for FCL since the objective is achieved with a lower value of FCL

\section{Effect of FCL type}

In the above, FCL is assumed to be an impedance having resistive and inductive components. However, FCL can be made of nearly pure resistance or nearly pure inductance. The cost of FCL depends on its structure type. For the same conditions given in section A above, the problem of FCL planning is solved using the proposed multiobjective formulation (with $\mathrm{F} 1$ and F2) assuming either resistive or inductive FCL. They both produce only one FCL at the utility source which is the same location as before. For the resistive FCL type, the value of the FCL resistance is 0.735 p.u with a value of 0.922 p.u for the objective function F1. For the inductive FCL, the value of the inductive reactance is $\mathrm{J} 0.729$ p.u with a value of 0.803 p.u for the objective function $\mathrm{F} 1$. It is noted that the impedance magnitude of the FCL is nearly equal for both types with a bit better current damping capability for the inductive type FCL. Both types maintain protection devices coordination. So, the cost of FCL can be a decisive factor in choosing the FCL type.

\section{Effect of DG location on FCL planning}

The two DG units basically located at bus 2 and bus 6 as depicted in Fig.5 are moved to other locations. The required FCLs are determined using the proposed multiobjective (F1 and F2) FCL planning algorithm under the rest of conditions as the same as section A. For all examined DG locations, the results indicate that only one composite-impedance FCL is required at the utility source. Its size depends on the new DG locations as given in Table V. It is observed that the location of DG units in a radial distribution network, like the one shown in Fig.5, has a minor effect on the FCL placement and sizing.

Table Veffect of dg location on fcl

\begin{tabular}{|l|l|l|l|}
\hline DG location & \multirow{2}{*}{ FCL size, p.u } & $\begin{array}{l}\text { Value of objective } \\
\text { function F1, p.u }\end{array}$ \\
\hline DG1 & DG2 & F & 0.7315 \\
\hline Bus 2 & bus 6 & J0.7401 & 0.9501 \\
\hline Bus 3 & bus 7 & J0.7498 & 1.0027 \\
\hline Bus 4 & bus 8 & $\mathbf{0 . 0 0 8 7 + J 0 . 7 4 4 5}$ & $\mathbf{1 . 0 0 4 1}$ \\
\hline Bus 5 & bus 9 & $\mathbf{0 . 0 7 3 1 + J 0 . 7 1 8 2}$ & $\mathbf{r}$ \\
\cline { 1 - 2 }
\end{tabular}

\section{Effect of DG size}

The size of the two DG units located at bus 2 and bus 6 as depicted in Fig.5 are changed. The required FCLs are determined using the proposed multi-objective (F1 and F2) FCL planning algorithm under the rest of conditions as the same as section A. Up to a certain penetration level of DG, the results indicate that only one composite-impedance FCL is required at the utility source. If this level is exceeded, more FCL units can be needed. Generally, FCL size depends on the new DG size as given in Table VI. It is obvious that the size of DG units in a radial distribution network, like the one shown in Fig.4, has a significant effect on the FCL placement and sizing.

\section{Effect of system configuration on FCL}

When a tie switch is closed between bus 5 and bus 9, the system is converted from radial system to looped (meshed) system. Table VII compares the results of optimal FCL of this new configuration to that of radial configuration shown in Fig.5 using the proposed multi- objective formulation of the problem considering $\mathrm{F} 1$ and $\mathrm{F} 2$ as the objectives of interest. It is noticed that both configurations require only one FCL at the utility source with almost equal sizes. However, this FCL is seen to be more 
efficient in the looped configuration as it causes greater damping of branches fault current reflected in much less value of the objective function F1 compared to the radial configuration.

Table VI effect of dg size on fcl

\begin{tabular}{|c|c|c|c|c|c|c|}
\hline \multicolumn{2}{|c|}{$\begin{array}{c}\text { DG size, } \\
\text { MVA }\end{array}$} & \multirow{2}{*}{$\begin{array}{c}\text { DG } \\
\text { dat } \\
\text { a }\end{array}$} & \multirow{2}{*}{$\begin{array}{l}\text { Utility source } \\
\text { FCL size, p.u }\end{array}$} & \multirow{2}{*}{$\begin{array}{c}\text { DG FCL } \\
\text { size, p.u }\end{array}$} & \multicolumn{2}{|c|}{$\begin{array}{l}\text { Value of } \\
\text { objective } \\
\text { functions }\end{array}$} \\
\hline $\begin{array}{c}\text { DG } \\
1\end{array}$ & $\begin{array}{c}\text { DG } \\
2\end{array}$ & & & & F1, p.u & $\begin{array}{l}\text { F2, } \\
\text { p.u }\end{array}$ \\
\hline 1.5 & 1.5 & [25] & $0.002+J 0.0684$ & $\mathbf{0}$ & 0.0046 & 0.0704 \\
\hline 3.75 & 3.75 & [25] & $\mathbf{0 . 0 1 + J 0 . 1 3 1 3}$ & $\mathbf{0}$ & 0.0238 & 0.1413 \\
\hline 8 & 8 & [20] & J0.7401 & $\mathbf{0}$ & 0.7315 & 0.7401 \\
\hline 0 & 30.4 & 26] & $\begin{array}{c}0.0103+\mathrm{J} 0.360 \\
4\end{array}$ & $\begin{array}{l}\text { 0.0509+ } \\
\text { J0.6664 }\end{array}$ & 0.1245 & 1.088 \\
\hline
\end{tabular}

Table VII effect of system configuration on fcl

\begin{tabular}{|c|c|c|c|}
\hline \multirow{2}{*}{ configuration } & \multirow{2}{*}{$\begin{array}{c}\text { Utility source } \\
\text { FCL size, p.u }\end{array}$} & \multicolumn{2}{|c|}{$\begin{array}{c}\text { Value of objective } \\
\text { functions }\end{array}$} \\
\cline { 3 - 4 } & & F1, p.u & F2, p.u \\
\hline looped & J0.7403 & $\mathbf{0 . 4 4 5 5}$ & $\mathbf{0 . 7 4 0 3}$ \\
\hline radial & J0.7401 & $\mathbf{0 . 7 3 1 5}$ & $\mathbf{0 . 7 4 0 1}$ \\
\hline
\end{tabular}

\section{B. 69-bus test system}

The optimal FCL component values are determined for the 69-bus test system depicted in Fig.8. The system data is given in [28]. This network has 7 reclosers, 68 fuses and 4DG units. It is desired to maintain the coordinated operation of these protection devices by installing FCLs. Each FCL is composed of a resistive component $(\mathrm{R})$ and an inductive component $(\mathrm{X})$ connected in series.

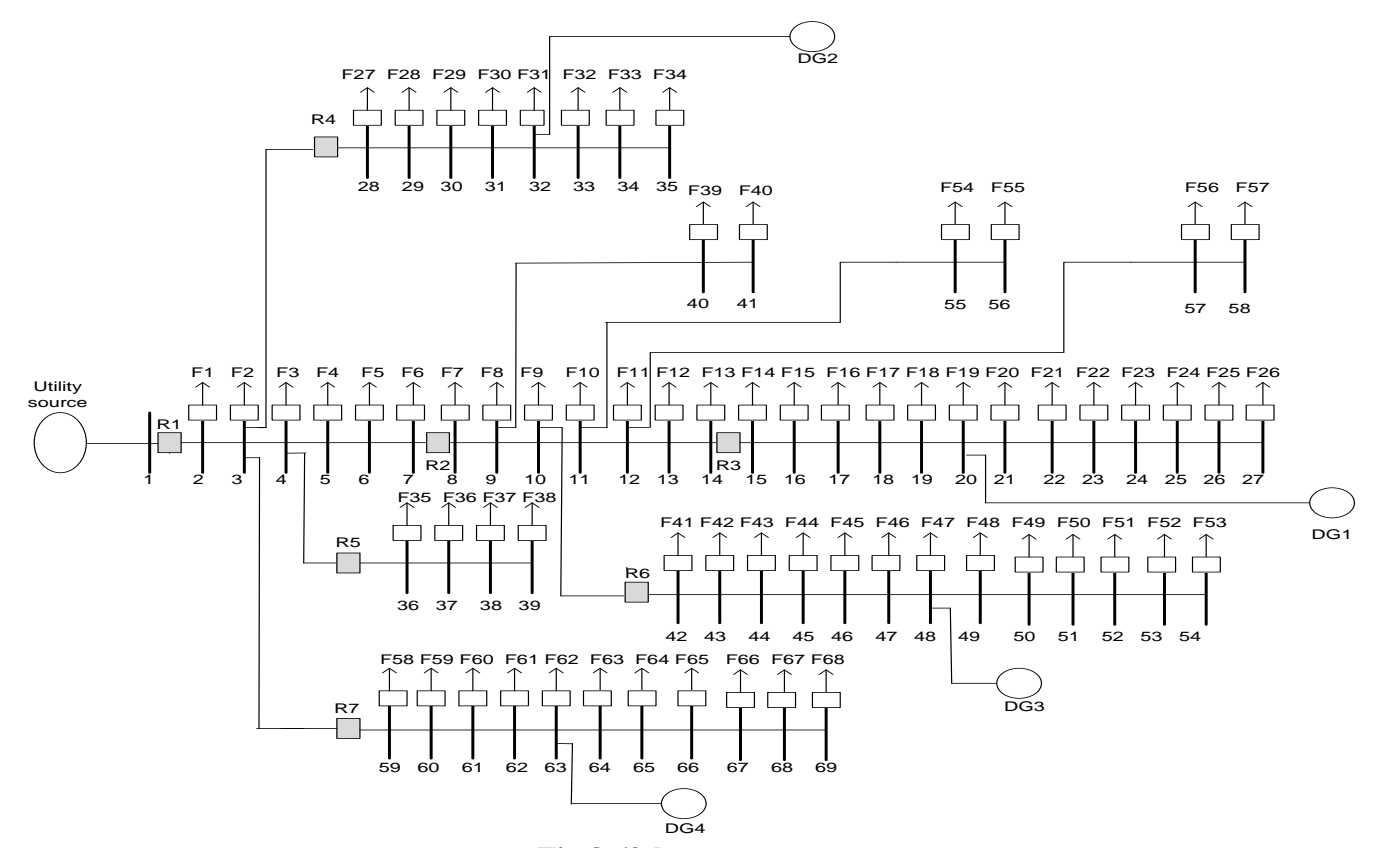

Fig.8 69-bus test system

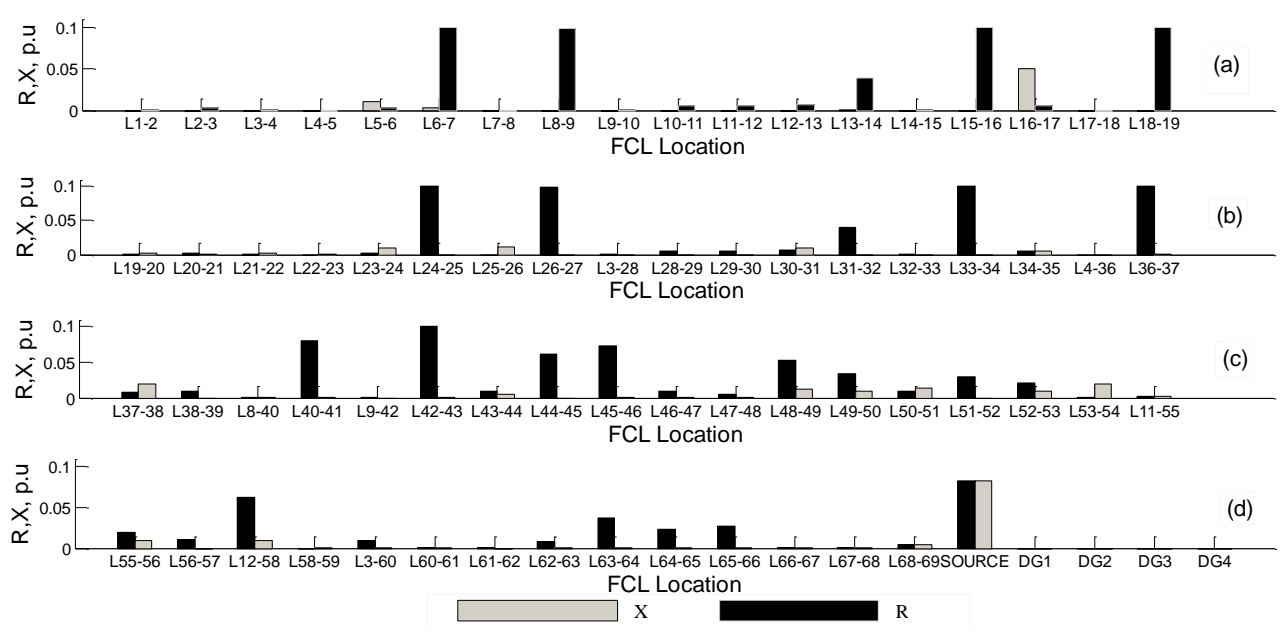

Fig.9 FCLs components sizes 
FCLs are allowed to be inserted in series to: each DG unit, utility source, and each feeder section. Solving the multi-objective optimization problem formed in section IV above, the results are given in Fig.9. The values of the three objective functions are $\mathrm{F} 1=35$ p.u, $\mathrm{F} 2=2.2$ p.u, $\mathrm{F} 3=0.44$ p.u. Determined FCLs components' sizes at possible locations are shown in Fig.9. Zero values of both $\mathrm{R}$ and $\mathrm{X}$ at some locations indicate that no FCL is needed at this location. It is noted that the required FCLs are mostly resistive. Values of $\mathrm{X}$ are generally very small. A big-size FCL is located in series to the utility power source. No FCLs are required in series to DG units. Fig.10 presents the symmetrical fault currents passing through the various protective devices under three conditions: without DG, with DG but without FCL, and with both DG and FCLs. The fuse currents are shown in Fig.10a and the recloser currents are shown in Fig.10b. It is noted that application of optimal FCLs reduces fault currents to nearly its values without DG. This maintains protection coordination even when DG is connected. Fig.11,(a),(b),(c),(d) depicts the nodes voltages for different symmetrical-fault locations when the optimal FCLs are installed with DG. It also compares the results for the base case (without DG) and the case of integrating DG without FCL. The FCL presence much improves the node voltage under fault conditions. This mitigates voltage sag and lessens the probability of critical loads tripping under fault conditions.

\section{Conclusion}

The fault current limiter is used to restore the recloser-fuse coordination in distribution system with DGs. The FCL allocation problem involves more than one objective function which are conflicting. So, it is formulated as a multi-objective constrained nonlinear programming problem to simultaneously minimize: the increase in fault current levels due to DGs, node voltage sag, and the total cost (size) of required limiters. The optimization problem is solved using PSO. The results obtained by the proposed formulation surpass those obtained by single-objective formulation. The former yields an adequate fault current damping at much reduced FCLs cost and tangibly mitigated node voltage sag. Including voltage sag requires small-size FCL to be installed in every section in the distribution system. Otherwise, few FCLs are generally required in series to power sources. The FCL after Source is found the best place for FCL since the objective is achieved with a lower value of FCL.DGs sizes, locations, types, and network topology evidently affect the FCLs allocation.
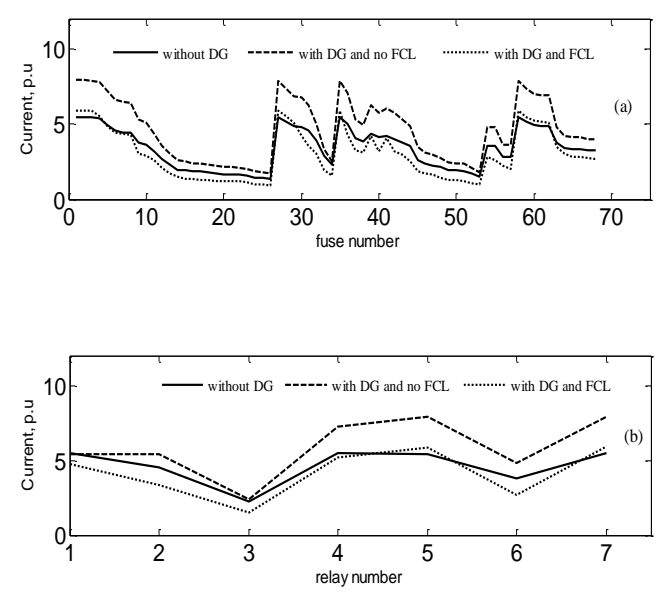

Fig.10 Primary device fault current

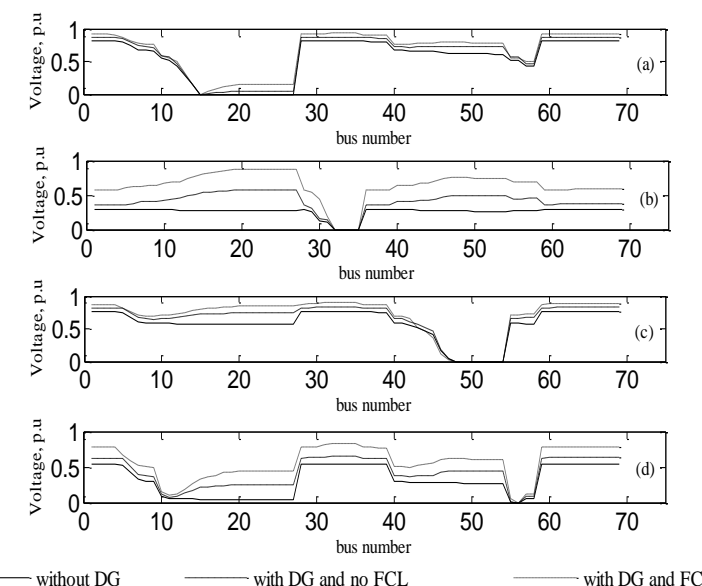

Fig.11 Node voltages for different faults 


\section{References}

[1] G. Tang, and M. R. Iravani, "Application of a Fault Current Limiter to Minimize Distributed Generation Impact on Coordinated Relay Protection," Presented at the International Conference on Power Systems Transients IPST'05, Montreal, Canada, June 19-23, 2005.

[2] U. Khan, "Impact of Distributed Generation on Electrical Power Network," www.wppt.pwr.wroc.pl.

[3] M. Begović, A. Pregelj, A. Rohatgi, "Impact of Renewable Distributed Generation on Power Systems,"Proceedings of the $34^{\text {th }}$ Hawaii International Conference on System Sciences, 2001.

[4] S. Chaitusaney, and A. Yokoyama,"Reliability Analysis of Distribution System with Distributed Generation Considering Loss of Protection Coordination," $\quad 9^{\text {th }}$ International Conference on Probabilistic Methods Applied to Power Systems, Stockholm, Sweden, June 11-15, pp.1-8, 2006.

[5] J. Sa'ed, S. Favuzza, M. Ippolito, F. Massaro, "An Investigation of Protection Devices Coordination Effects on Distributed Generators Capacity in Radial Distribution Systems," IEEE/PES Transmission and Distribution Conference and Exposition: Latin America, pp.110$115,2010$.

[6] S. Chaitusaney, and A. Yokoyama, A. Fazanehrafat, S. Javadian, S. Bathaee, and M. Haghifamt, "Maintaining The Recloser-Fuse Coordination in Distribution Systems in Presence of DG by Determining DG's Size," in Proc. IET $9^{\text {th }}$ International Conference on Developments in Power System Protection, 2008, pp. 132-137.

[7] S. Brahma and A. Girgis, "Microprocessor-Based Reclosing to coordinate Fuse and Recloser in a system with High Penetration of Distributed Generation," in Proc. IEEE
Power Engineering Society Winter Meeting, pp. 453 - 458, 2002.

[8] J. Gomez and M. Morcos, "Coordination of Voltage Sag and Overcurrent Protection in DG System "IEEE Transactions on Power Delivery, Vol. 20, No.1,pp. 214-218, 2005.

[9] S. Brahma and A. Girgis, "Development of Adaptive Protection Scheme for Distribution Systems With High Penetration of Distribution Generation," IEEE Transactions on Power Delivery, Vol. 19, No.1, pp. 5663, 2004.

[10] "Distribution Line Protection Practices Report," [Online], Available: http://www.pes-

psrc.org/Apublications.html, 2002.

[11] B. Hamed K. Butler-Purry, "An Approach to Mitigate the Impact of Distributed Generation on the Overcurrent Protection Scheme for Radial Feeders," IEEE/PES Power Systems Conference and Exposition, PSCE '09, pp.1-11, 2009.

[12] J. Martinez, and J. Martin-Arnedo, "Impact of Distributed Generation on Distribution Protection and Power Quality," IEEE Power \& Energy Society General Meeting, PES '09, pp.1-6, 2009.

[13] S. Chaitusaney, and A. Yokoyama, "Impact of Protection Coordination on Sizes of Several Distributed Generation Sources," The $7^{\text {th }}$ International Power Engineering Conference, IPEC 2005, Vol. 2, pp.669 - 674, 2005.

[14] K. Hongesombut, Y. Mitani and K. Tsuji, "Optimal Location Assignment and Design of Superconducting Fault Current Limiters Applied to Loop Power Systems" IEEE Transactions on Applied Superconductivity, Vol. 13, No. 2, pp. 1828 - 1831, June 2003.

[15] Jen-Hao Teng, Chan-Nan Lu, "Optimum Fault Current Limiter Placement." ISAP 2007, pp. 1- 6, 2007. 
[16] A.F. Naiem, Y. Hegazy, A.Y.Abdelaziz,

M.A.Elsharkawy,'Aclassitication technique for recloser-fuse coordination in distribution systems with distributed generation ', IEEE Transactions on power delivery, Vol. 27, No. 1, pp. 253 - 264, January 2012.

[17] A. Elmitwally, "Proposed Hybrid Superconducting Fault Current Limiter for Distribution Systems," International Journal of Electrical Power \& Energy Systems, Vol.31, No.10, pp.619-625, 2009.

[18] Sung-Hun Lim and Jae-Chul Kim, "Analysis on Protection Coordination of Protective Devices with a SFCL Due to the Application Location of a Dispersed Generation in a Power Distribution System.," IEEE Transactions on Applied Superconductivity, Vol.22, No.3, 2012.

[19] Y. Zhang, , and R. Dougal, "Novel Dual-FCL Connection for Adding Distributed Generation to a Power Distribution Utility," IEEE Transaction on Applied Superconductivity, Vol. 21, No. 3, June 2011.

[20] Y. Zhang and R. Dougal, "Specification of Fault Current Limitation Level for FCLs in Power Systems," Proceedings of the IEEE Southeast Con, pp. 246 - 249, 2010.

[21] G. Cakal, F. Bagriyanik, M. Bagriyanik, "The Effect of Fault Current Limiters on Distribution Systems with Wind Turbine Generators," International journal of Renewable Energy Research," Vol.3, No.1, 2013.

[22] H. Zeineldin, and W. Xiao, "Optimal Fault Current Limiter Sizing for Distribution Systems with DG," IEEE Power \& Energy Society General Meeting, pp.1-5, 2011.
[23] M. Reyes-sierra, C. Coello, "MultiObjective Particle Swarm Optimizers: A Survey of the State-of-the-Art," International Journal of Computational Intelligence Research,Vol.2, No.3, pp. 287-308, 2006.

[24] Jong-Bae Park, Ki-Song Lee, JoongRin Shin, and Kwang Lee, "A Particle Swarm Optimization for Economic Dispatch With Non smooth Cost Functions," IEEE Transactions on Power Systems, Vol. 20, No. 1, 2005.

[25] M. Chen, C. Zhang and C. Luo, "Adaptive evolutionary multiobjective particle swarm optimization algorithm," Control and Decision, Vol. 24, No. 12, pp.1851-1855, 2009.

[26] "Distributed Generation Modeling Guidelines," Synchronous Machine Data EPRI TR1000418.

[27] "Talkha Gas Turbine Power plant," www.moee.gov.eg

[28] Saeid Soudi, "Distribution System Planning With Distributed Generations Considering Benefits and Costs," I. J. Modern Education and Computer Science, Vol.9, pp.45-52, 2013. 